\title{
Numerical study of one-dimensional compression in granular materials
}

\author{
J. C. LOPERA PEREZ* , C. Y. KWOK*, C. O’SULLIVAN $\dagger$, X. HUANG*† and K. J. HANLEY†t
}

\begin{abstract}
The discrete element method has been employed to simulate vertical one-dimensional compression of an idealised soil. Direct measurement of the full stress tensor was possible and the results show that $K_{0}$ (the ratio of horizontal to vertical effective stresses) increases with void ratio, which is consistent with previous experimental studies. The anisotropic fabric induced during compression was quantified by considering the orientations and magnitudes of the normal contact forces. For the denser samples there was a definite bias towards more vertically oriented contacts, resulting in lower stresses being transmitted in the horizontal direction for a given vertical stress. In contrast, the contacts were oriented more isotropically in the looser samples, allowing more similar stresses to be transmitted in the horizontal and vertical directions.
\end{abstract}

KEYWORDS: discrete-element modelling; fabric/structure of soils; particle-scale behaviour

ICE Publishing: all rights reserved

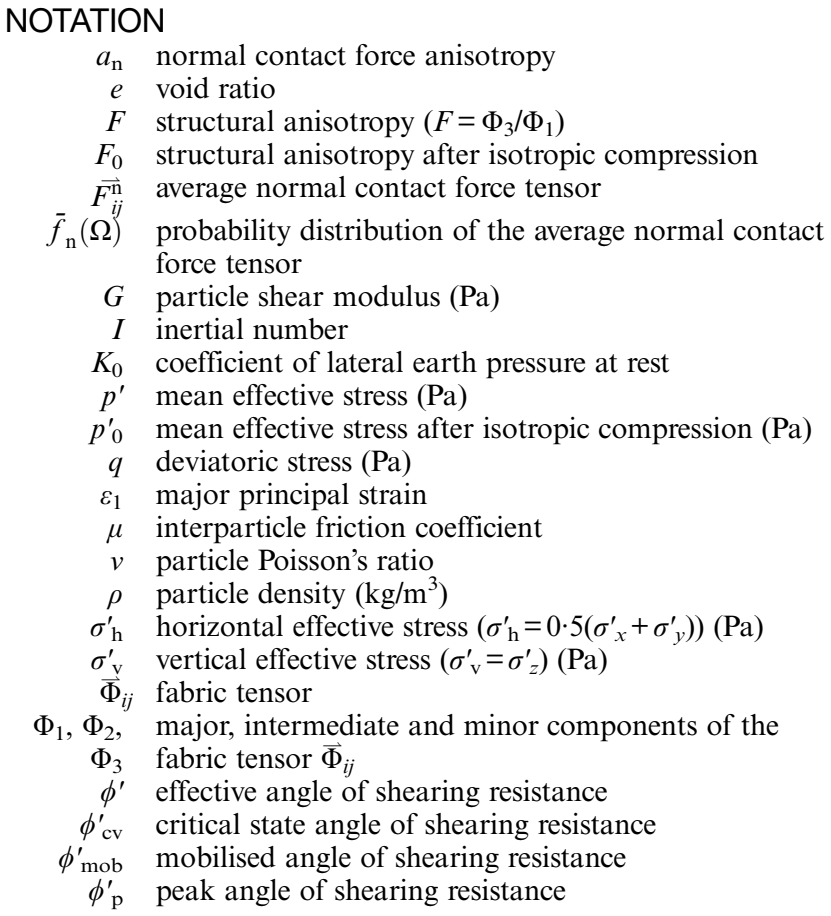

\section{INTRODUCTION}

The coefficient of lateral earth pressure at rest $\left(K_{0}\right)$, defined as the ratio of horizontal effective stress $\left(\sigma_{\mathrm{h}}^{\prime}\right)$ to vertical effective stress $\left(\sigma_{\mathrm{v}}^{\prime}\right)$ measured under zero lateral strain conditions, is an important parameter used for the design

Manuscript received 27 November 2014; first decision 9 February 2015; accepted 6 April 2015.

Published online at www.geotechniqueletters.com on 24 July 2015.

*Department of Civil Engineering, The University of Hong Kong, Hong Kong

$\dagger$ Department of Civil and Environmental Engineering, Imperial College London, London, UK

tInstitute for Infrastructure and Environment, School of Engineering, The University of Edinburgh, Edinburgh, UK of geotechnical structures. Measurement of horizontal effective stresses is non-trivial and so practising engineers tend to use the formula put forward by Jaky (1944), which correlates $K_{0}$ to the angle of shearing resistance

$$
K_{0}=1-\sin \phi^{\prime}
$$

where $\phi^{\prime}$ is the effective angle of shearing resistance, which is often taken as the angle of shearing resistance at the critical state $\left(\phi_{\text {cv }}^{\prime}\right)(J a k y, 1944 ;$ Mesri \& Hayat, 1993). This definition implies that there is a unique $K_{0}$ value for a given soil type and that $K_{0}$ is independent of initial state (i.e. packing density and stress level). The angle of shearing resistance at peak stress $\left(\phi_{\mathrm{p}}^{\prime}\right)$ is sometimes used in equation (1) (Mesri \& Vardhanabhuti, 2007; Talesnick, 2012; Lee et al., 2013); $\phi_{\mathrm{p}}^{\prime}$ depends on the material state (Been \& Jefferies, 1985) and thus if $\phi_{\mathrm{p}}^{\prime}$ is used in equation (1), at a given stress level, $K_{0}$ will increase with increasing void ratio. While Jaky's equation has been successfully applied in a large range of engineering applications, it may fail to predict the measured $K_{0}$ as it does not consider certain factors in granular materials that may affect the $K_{0}$ value. $K_{0}$ experiments conducted by Chu \& Gan (2004) and Wanatowski \& Chu (2007) found relatively high $K_{0}$ values and a marked sensitivity of the $K_{0}$ response to the initial void ratio $\left(e_{0}\right)$ for loose sand samples; for denser sands, the $K_{0}$ values were lower and less sensitive to variations in packing density. Similar observations were reported by Okochi \& Tatsuoka (1984), Mesri \& Vardhanabhuti (2007), Lee et al. (2013) and Northcutt \& Wijewickreme (2013). In contrast, Talesnick (2012) reported higher $K_{0}$ values for dense states than for loose ones. It is worth mentioning that differences in the experimental procedures, testing devices, sample preparation techniques and data acquisition methods between the studies likely influence any variation in the observed $K_{0}$-void ratio dependency.

Differences in size, shape or roughness of particles also influence the measured $K_{0}$ values. Lee et al. (2013) measured higher values of $K_{0}$ for non-etched glass beads than for etched glass beads. Furthermore, sub-angular and angular particles showed lower values of $K_{0}$ than glass beads. Changes in particle shape and hence in the connectivity of particles affect the fabric of granular materials, which is 
closely related to the $K_{0}$ value (Guo \& Stolle, 2006; Northcutt \& Wijewickreme, 2013).

Lee et al. (2013) attributed the low $K_{0}$ values obtained for dense materials to the development of strong force chains in the vertical direction, leading to less stress transmission in the horizontal direction. However, Talesnick (2012) attributed the high $K_{0}$ values for dense materials to the dilatant nature of dense soils, but it is difficult to accept this explanation as dilation is suppressed during one-dimensional (1D) compression.

The aim of the current article is to develop a science-based fundamental understanding of the dependency of $K_{0}$ on void ratio. Discrete element method (DEM) simulations of 1D compression tests were performed; the stresses could be directly calculated from the contact forces and so the vertical and horizontal stresses could be quantified accurately, which is difficult to achieve in physical experiments.

\section{DEM SIMULATIONS}

This study used a modified version of the open-source code Lammps (Plimpton, 1995). Three-dimensional numerical samples were created as a representative volume element consisting of 22312 initially non-contacting spherical particles enclosed by periodic boundaries. These boundary conditions eliminate inhomogeneities (Thornton, 2000; Huang et al., 2014a). The particle size distribution (PSD) used for all simulations is representative of Toyoura sand (Fig. 1). A simplified Hertz-Mindlin contact model was used. The input parameters used were shear modulus $G=$ $29 \mathrm{GPa}$, particle Poisson's ratio $v=0 \cdot 12$, particle density $\rho=2650 \mathrm{~kg} / \mathrm{m}^{3}$ and local damping coefficient $=0 \cdot 1$. Initially, the periodic cell was deformed until the system reached an isotropic stress state with an initial mean effective stress $\left(p_{0}^{\prime}\right)$ of $25 \mathrm{kPa}$. After reaching the desired $p_{0}^{\prime}$, the system was subjected to numerical cycling until $p^{\prime}$ and the number of contacts became constant, indicating equilibrium. Ten samples were created and the initial void ratio $\left(e_{0}\right)$ of each sample was controlled using different interparticle friction coefficients $(\mu)$ during the isotropic compression stage, as indicated in Table 1.

Once the isotropic compression stage was completed, $\mu$ was set to 0.25 (Huang et al., 2014b). One-dimensional

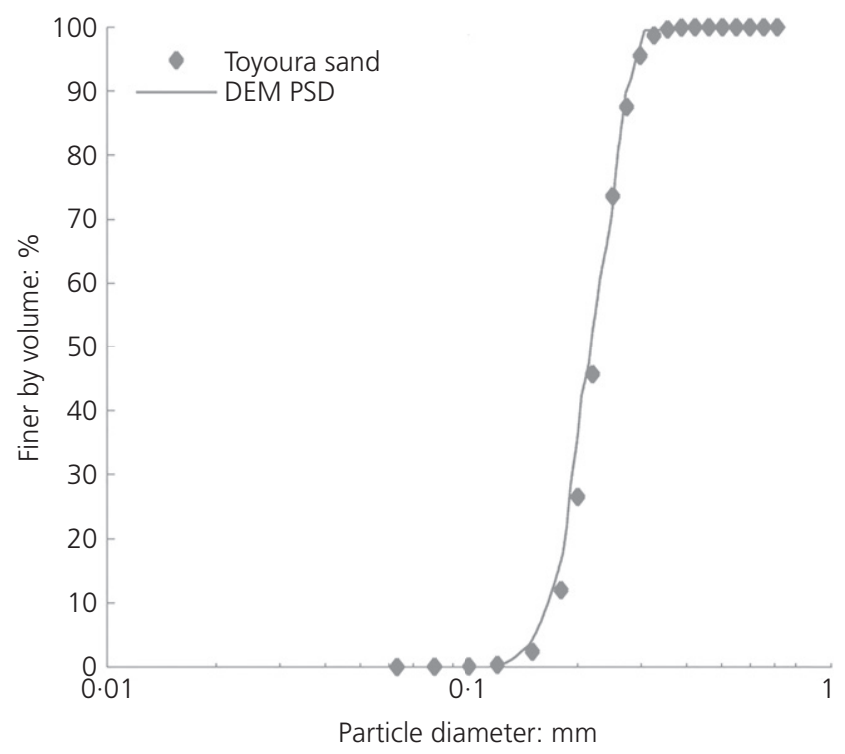

Fig. 1. Particle size distribution of numerical samples compared with laboratory data for Toyoura sand
Table 1. Summary of numerical $K_{0}$ tests conducted

\begin{tabular}{l|c|c}
\hline $\begin{array}{l}\text { Test } \\
\text { ID }\end{array}$ & $\begin{array}{c}\mu \text { during isotropic } \\
\text { compression }\end{array}$ & $\begin{array}{c}e_{0} \text { (after isotropic } \\
\text { compression) }\end{array}$ \\
\hline K0-1 & $5 \cdot 0 \times 10^{-4}$ & 0.544 \\
K0-2 & $1 \cdot 0 \times 10^{-3}$ & 0.543 \\
K0-3 & $1 \cdot 0 \times 10^{-2}$ & 0.561 \\
K0-4 & $5 \cdot 0 \times 10^{-2}$ & 0.598 \\
K0-5 & $0 \cdot 110$ & 0.630 \\
K0-6 & $0 \cdot 150$ & 0.645 \\
K0-7 & $0 \cdot 190$ & 0.659 \\
K0-8 & $0 \cdot 200$ & 0.661 \\
K0-9 & $0 \cdot 215$ & 0.664 \\
K0-10 & 0.235 & 0.669 \\
\hline
\end{tabular}

compression was then simulated by deforming the periodic cell: the top boundary was moved at a constant velocity in the vertical direction while the horizontal and bottom boundaries were maintained in a fixed position. The velocity chosen was sufficiently small to ensure that the system was maintained in the quasi-static regime (i.e. inertial number $\left.I \leq 2 \cdot 5 \times 10^{-3}\right)($ GDR MiDi, 2004; da Cruz et al., 2005). The stresses in the periodic cell were determined using the particle and contact force data (Bagi, 1996; Potyondy \& Cundall, 2004). Ten triaxial tests were carried out to define the $e_{0}-\phi_{\mathrm{p}}^{\prime}$ relationship and to obtain $\phi_{\mathrm{cv}}^{\prime}$ for the simulated sand. Details of the triaxial simulations and corresponding results are shown in Table 2.

\section{RESULTS}

\section{Macro response}

Results from six representative 1D compression tests are plotted in Fig. 2. The initial void ratios at the start of compression ranged from $e_{0}=0.544$ for the densest sample to $e_{0}=0.664$ corresponding to the loosest of these six samples. Tests were terminated at mean effective stress values of $p^{\prime}=$ $750-950 \mathrm{kPa}$. Referring to Fig. 2(a), the effective stress ratio $\left(q / p^{\prime}\right)$ decreased as $e_{0}$ increased. Figure 2(b) indicates that the axial strain level $\left(\varepsilon_{1}\right)$ at which a given value of $q$ was reached increased with $e_{0}$. For the densest sample $\left(e_{0}=\right.$ $0.544), q=100 \mathrm{kPa}$ was achieved at $\varepsilon_{1} \approx 0.07 \%$; for the loosest sample, $\varepsilon_{1}$ exceeded $0 \cdot 25 \%$ at the same $q$ level. Figure 2 also includes results from laboratory tests reported by Wanatowski \& Chu (2007) and Chu \& Gan (2004), which indicate that the observations from the simulations are qualitatively consistent with experimental data.

The horizontal stresses were calculated as the mean value of $\sigma_{x}^{\prime}$ and $\sigma_{y}^{\prime}$. Figure 3(a) illustrates the variation of $K_{0}$ with effective vertical stress $\left(\sigma_{\mathrm{v}}^{\prime}\right)$, while Fig. 3(b) illustrates the variation in $K_{0}$ with the major principal strain $\left(\varepsilon_{1}\right)$ (i.e. the

Table 2. Summary of data from triaxial simulations

\begin{tabular}{l|l|l|c|c}
\hline Test ID & \multicolumn{1}{|c|}{$e_{0}$} & $\begin{array}{l}p_{0}^{\prime}: \\
\mathrm{kPa}\end{array}$ & $\begin{array}{c}\phi_{\mathrm{p}}^{\prime}: \\
\text { degrees }\end{array}$ & $\begin{array}{c}\phi_{\mathrm{cv}}^{\prime}: \\
\text { degrees }\end{array}$ \\
\hline TX-CD-100-0.5928 & $0 \cdot 5928$ & 100 & $20 \cdot 10$ & $17 \cdot 82$ \\
TX-CD-500-0.5533 & $0 \cdot 5533$ & 500 & $22 \cdot 73$ & $17 \cdot 82$ \\
TX-CD-500-0.6059 & $0 \cdot 6059$ & 500 & $19 \cdot 65$ & $17 \cdot 82$ \\
TX-CD-500-0.6142 & $0 \cdot 6142$ & 500 & $19 \cdot 21$ & $17 \cdot 82$ \\
TX-CD-500-0.6615 & $0 \cdot 6615$ & 500 & $17 \cdot 82$ & $17 \cdot 82$ \\
TX-CD-1000-0.6142 & $0 \cdot 6142$ & 1000 & $19 \cdot 00$ & $17 \cdot 82$ \\
TX-CD-2500-0.5781 & $0 \cdot 5781$ & 2500 & $20 \cdot 80$ & $17 \cdot 82$ \\
TX-CD-5000-0.6482 & $0 \cdot 6482$ & 5000 & $17 \cdot 82$ & $17 \cdot 82$ \\
TX-CV-500-0.6238 & $0 \cdot 6238$ & 500 & $19 \cdot 27$ & $17 \cdot 82$ \\
TX-CV-500-0.6280 & $0 \cdot 6280$ & 500 & $19 \cdot 13$ & $17 \cdot 82$ \\
\hline
\end{tabular}




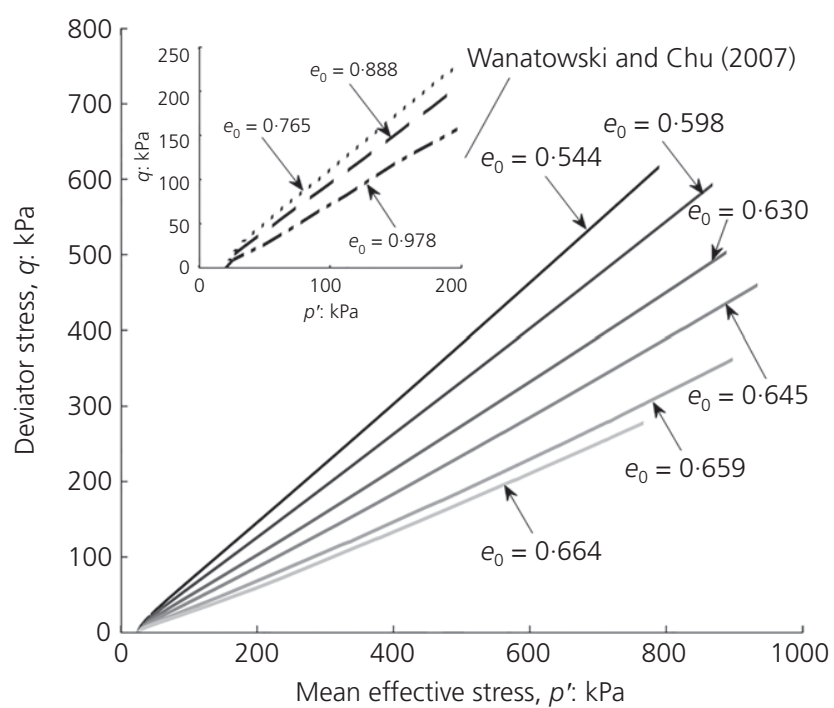

(a)

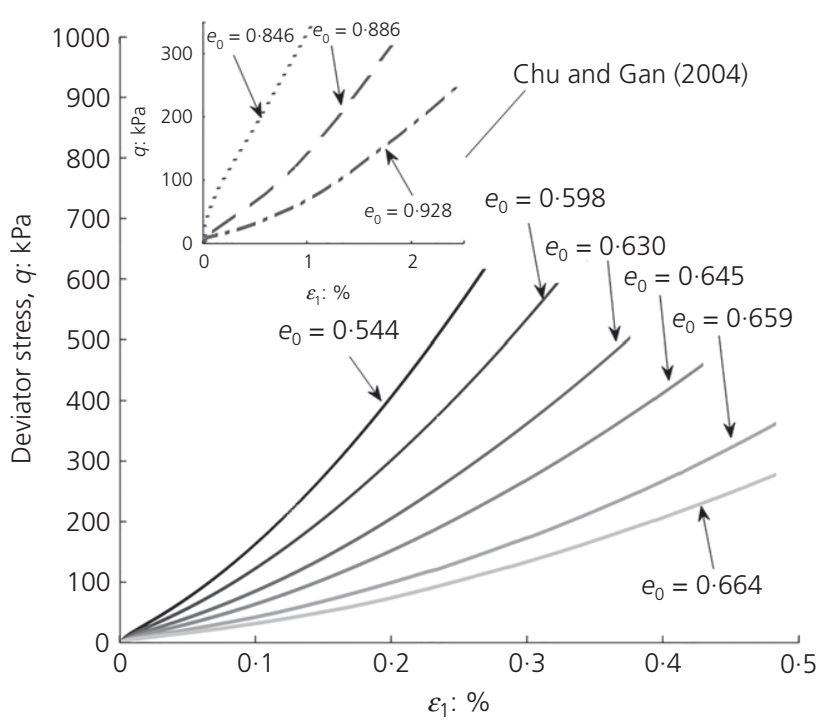

(b)

Fig. 2. Results from $K_{0}$ tests: (a) effective stress paths $q$ versus $p^{\prime}$; (b) stress-strain curves $q$ versus $\varepsilon_{1}$. Experimental data after Wanatowski \& Chu (2007) and Chu \& Gan (2004) are presented in the inset figures

vertical strain); both sets of data illustrate a clear dependency of $K_{0}$ on $e_{0}$. Generally, loose samples attained higher $K_{0}$ values than denser samples, in line with previous experimental observations by Chu \& Gan (2004), Wanatowski \& Chu (2007) and Okochi \& Tatsuoka (1984), which are included in Fig. 3 for comparison. Interestingly, while different preparation methods were used in the experimental studies (i.e. air pluviation (Okochi \& Tatsuoka, 1984) or moist tamping (Chu \& Gan, 2004; Wanatowski \& Chu, 2007)) and different initial stress conditions were applied, the trend is more or less the same for all the experiments and DEM simulations. Note that $K_{0}$ did not reach a constant value when plotted against either $\sigma_{\mathrm{v}}^{\prime}$ or $\varepsilon_{1}$, but decreased continuously for all samples, indicating that $K_{0}$ depends on $\sigma_{\mathrm{v}}^{\prime}$ and $\varepsilon_{1}$.

Figure 4(a) shows the variation of $K_{0}$ with initial void ratio at three discrete values of $\sigma_{\mathrm{v}}^{\prime}$, while Fig. 4(b) gives $K_{0}$ at three discrete $\varepsilon_{1}$ values. For each value of $\sigma_{\mathrm{v}}^{\prime}$ or $\varepsilon_{1}$ considered, the relationship between $K_{0}$ and void ratio can be represented by a power-law equation. Laboratory data in terms of $K_{0}$ and $e_{0}$

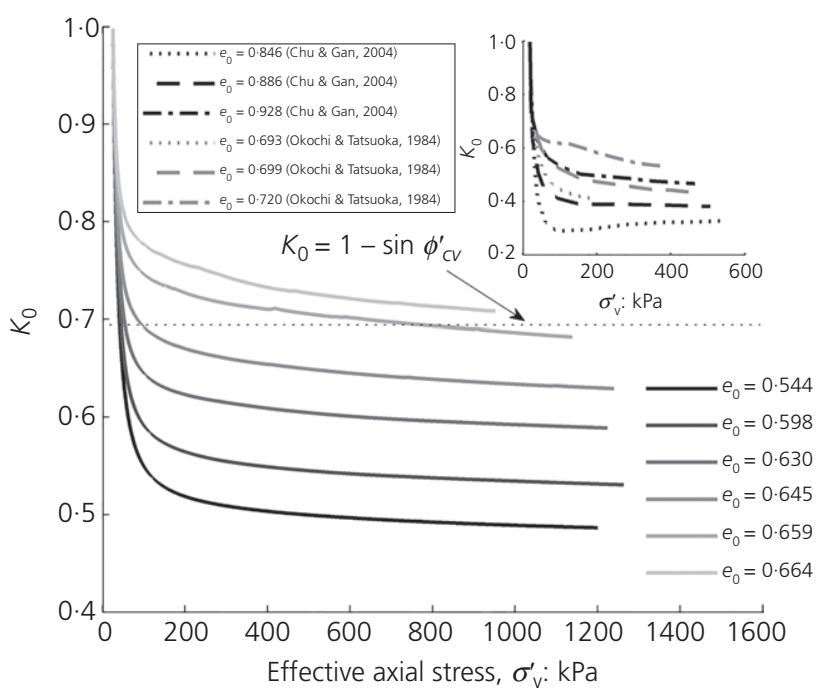

(a)

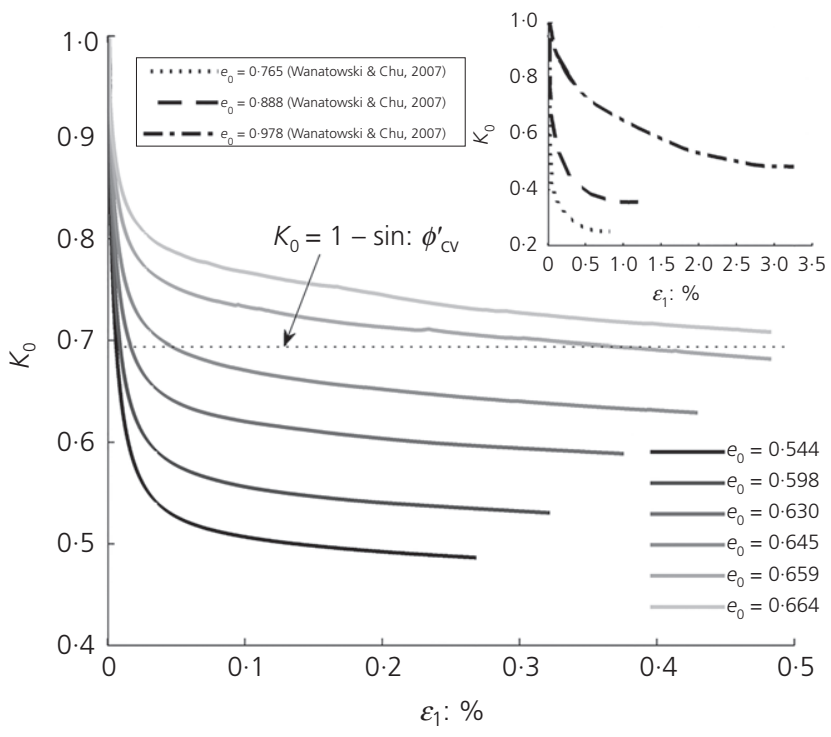

(b)

Fig. 3. Results from $K_{0}$ tests: (a) $K_{0}$ versus $\sigma^{\prime}$; (b) $K_{0}$ versus $\varepsilon_{1}$. The insets show experimental data from Chu \& Gan (2004), Okochi \& Tatsuoka (1984) and Wanatowski \& Chu (2007)

were collected and are also plotted in Fig. 4 for comparison. The dashed lines correspond to Jaky's equation used by Wanatowski \& Chu (2007) from plane strain and triaxial tests. Generally, $K_{0}$ values obtained in the DEM simulations and laboratory tests increase with increasing $e_{0}$. A power-law relationship between $K_{0}$ and $e_{0}$ was identified for the numerical data. This relationship differs from the linear $K_{0}-e_{0}$ relationship observed and proposed by Chu \& Gan (2004) and Wanatowski \& Chu (2007) for loose marine sand samples prepared by moist tamping (MT) and water sedimentation (WS) methods. Results from Hendron (1963) indicate a more gentle linear increase of $K_{0}$ with $e_{0}$ for rounded Minnesota sand. A steeper response was found for Toyoura sand, as reported by Okochi \& Tatsuoka (1984). The $K_{0}$ values for Toyoura sand are closer to those from the numerical tests than other types of sand. Figure 4(a) illustrates a similar dependency of $K_{0}$ on $\sigma_{\mathrm{v}}^{\prime}$ observed by Okochi \& Tatsuoka (1984). The differences between the magnitudes of $K_{0}$ for the physical sands tested and the numerical simulations can be attributed to particle size, shape (perfect spheres, angular and sub-angular sands) and differences in 


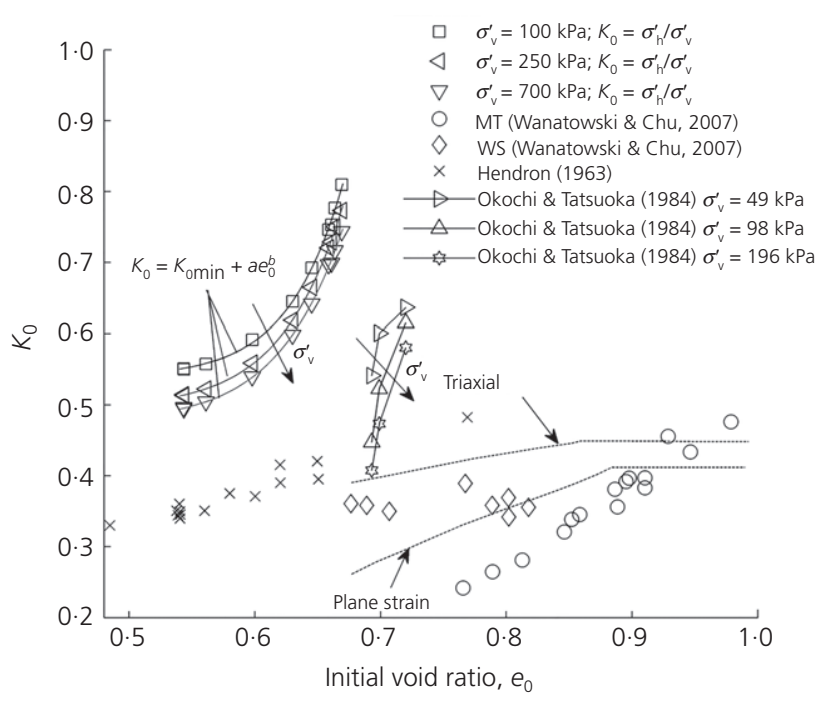

(a)

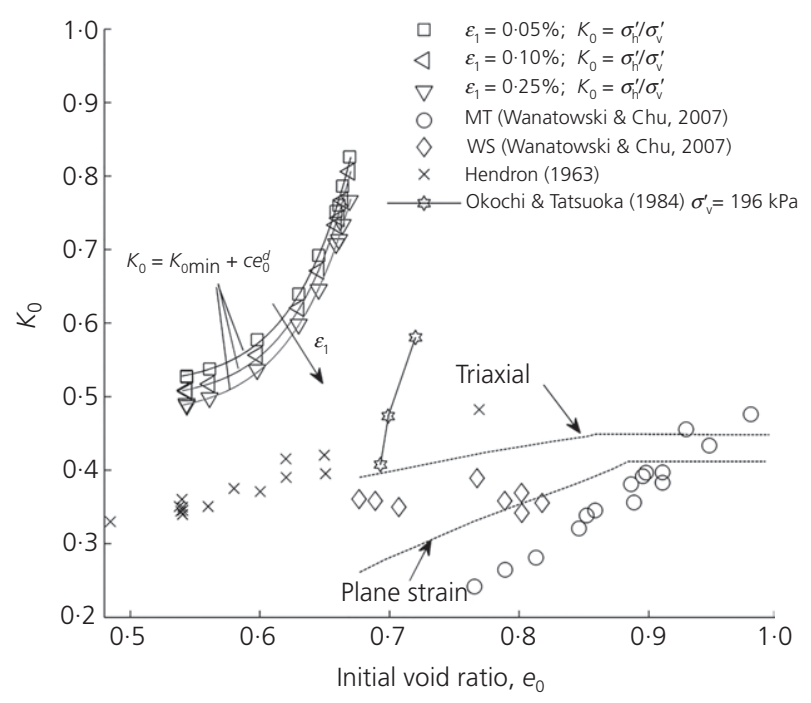

(b)

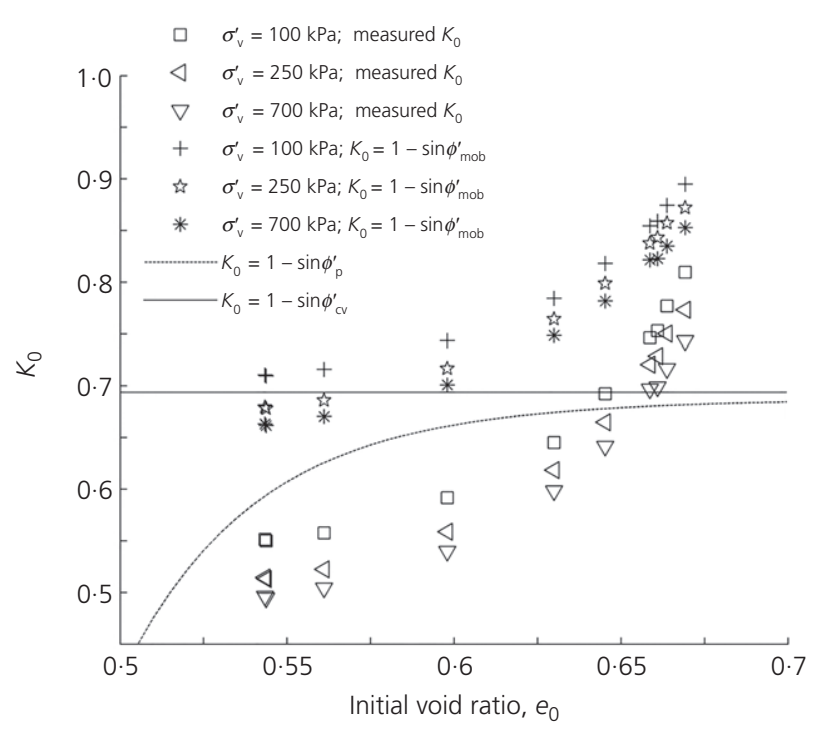

(c)

Fig. 4. $K_{0}$ against void ratio at different levels of $\sigma^{\prime}{ }_{v}(a)$ and at different stages of $\varepsilon_{1}$ (b); experimental data after Hendron (1963), Okochi \& Tatsuoka (1984) and Wanatowski \& Chu (2007). (c) Measured $K_{0}$ at different levels of $\sigma^{\prime}{ }_{v}$ and predicted values applying $\phi_{\mathrm{mob}}^{\prime}, \phi_{\mathrm{p}}^{\prime}$ and $\phi_{\mathrm{cv}}^{\prime}$ into Jaky's equation initial anisotropies (Guo \& Stolle, 2006). It is important to note, however, that in the current study structural anisotropy was induced entirely by the strain path imposed, while in the experimental studies, there will be an initial anisotropic structure as a consequence of gravity deposition during sample preparation.

Figure 4(c) compares measured $K_{0}$ values with predicted $K_{0}$ values from Jaky's equation using $\phi_{\mathrm{p}}^{\prime}, \phi_{\mathrm{cv}}^{\prime}$ and the angle of shearing resistance mobilised during the $1 \mathrm{D}$ compression tests $\left(\phi_{\text {mob }}^{\prime}\right)$, calculated from

$$
\sin \phi_{\mathrm{mob}}^{\prime}=\frac{\sigma_{\mathrm{v}}^{\prime}-\sigma_{\mathrm{h}}^{\prime}}{\sigma_{\mathrm{v}}^{\prime}+\sigma_{\mathrm{h}}^{\prime}}
$$

at the same discrete values of $\sigma_{\mathrm{v}}^{\prime}$ where $K_{0}$ was directly measured. From the triaxial results shown in Table 2 , an exponential relationship between $\phi_{\mathrm{p}}^{\prime}$ and $e_{0}$ as observed by Wanatowski \& Chu (2006) is evident and thus the $K_{0}-e_{0}$ relationship is established. For the case of $\sigma_{\mathrm{v}}^{\prime}=700 \mathrm{kPa}$, Jaky's equation overestimates the $K_{0}$ values for dense samples $\left(e_{0}<0.65\right)$ by as much as 0.12 considering $\phi_{\mathrm{p}}^{\prime}$ as input for Jaky's formula; for looser samples $\left(e_{0}>0 \cdot 65\right), K_{0}$ is underestimated by up to 0.05 when $\phi_{\mathrm{cv}}^{\prime}$ is used. Similar findings are presented by Wanatowski \& Chu (2007), as indicated in Fig. 4(a), which are consistent with how Jaky (1944) derived equation (1), by considering a normally consolidated mass of soil in a loose condition and thus giving better predictions for loose states when considering $\phi_{\text {cv. }}^{\prime}$. The data points calculated for $K_{0}$ using $\phi_{\text {mob }}^{\prime}$ in Jaky's equation are located above those measured in the numerical simulations. Considering that the ratio of horizontal to vertical stresses can be expressed as $\left(1-\sin \phi_{\text {mob }}^{\prime}\right) /$ $\left(1+\sin \phi_{\text {mob }}^{\prime}\right)$, applying $\phi_{\text {mob }}^{\prime}$ in Jaky's equation would displace the predicted values from those measured. The variance of the numerical $K_{0}$ is in line with those reported from laboratory experiments. This can be observed in Fig. 5, which shows $K_{0}$ against $\phi_{\text {cv }}^{\prime}$ for a range of soils including sands and clays as summarised by Wood (1990) based on results from Wroth (1972) and Ladd et al. (1977). Jaky's equation is also included in Fig. 5: the experimental results are enclosed between $-0 \cdot 20$ and $+0 \cdot 12$ from Jaky's equation, with the numerical results also falling between these limits.

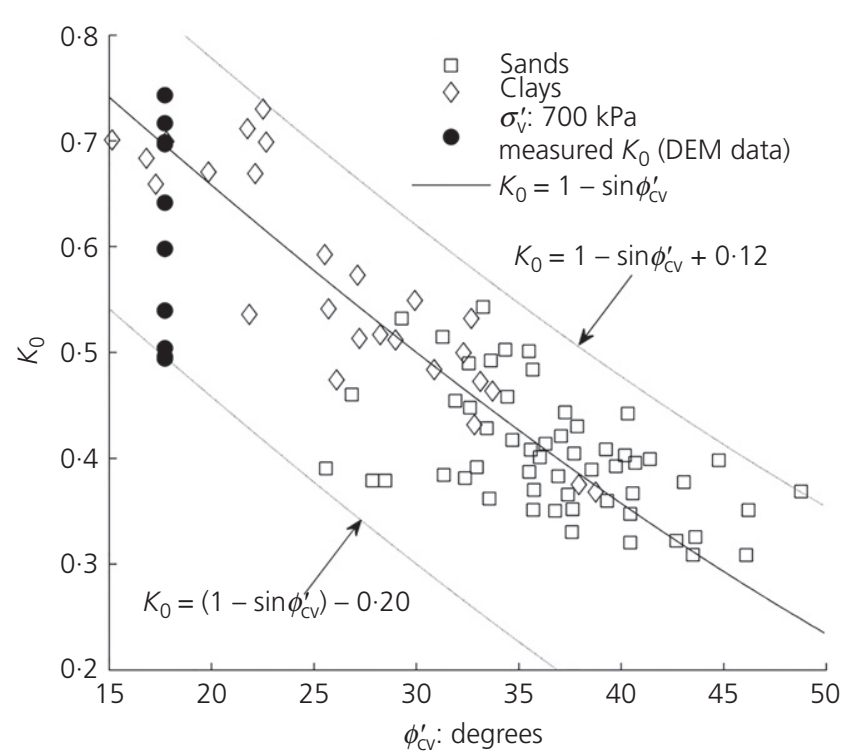

Fig. 5. Experimental data of $K_{0}$ for normally compressed soils together with numerical data from this study; experimental data after Wroth (1972) and Ladd et al. (1977) 


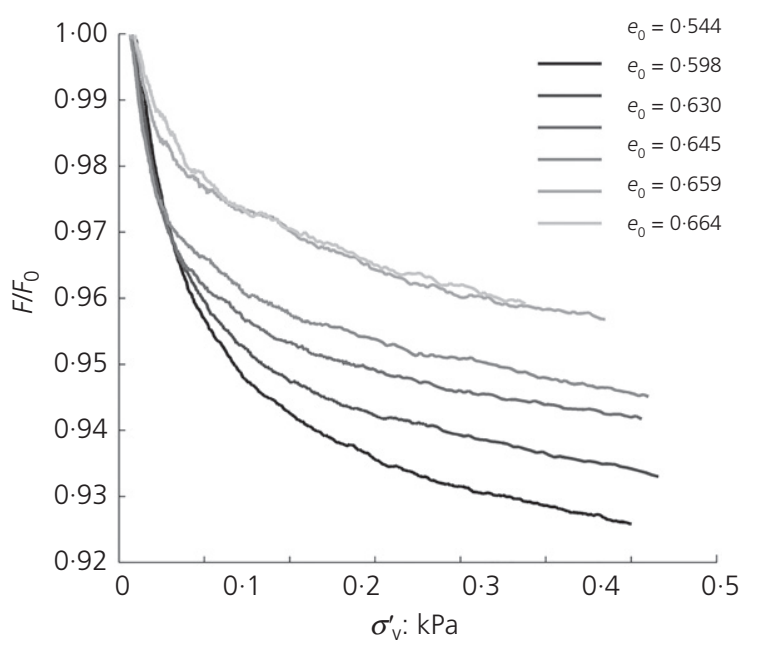

(a)

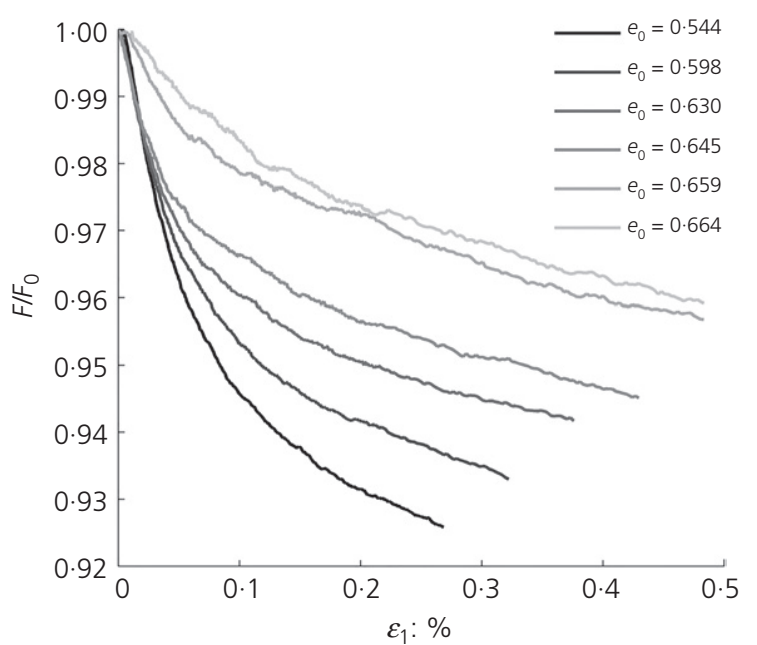

(b)

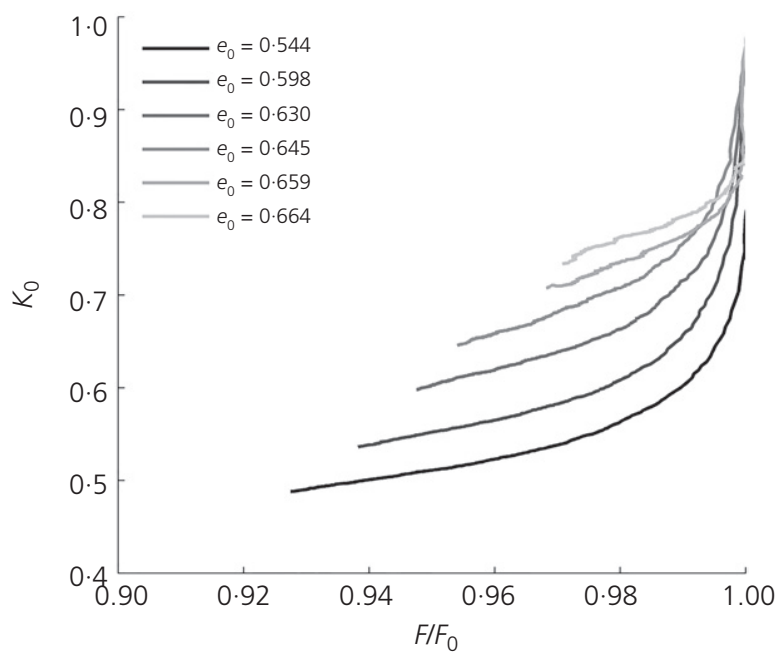

(c)

Fig. 6. Normalised degree of structural anisotropy: (a) $F / F_{0}$ versus $\sigma_{v}^{\prime}$; (b) $F / F_{0}$ versus $\varepsilon_{1}$; (c) $K_{0}$ versus $F / F_{0}$

\section{Micro-scale analysis}

Prior authors have attributed the $K_{0}$ dependency on void ratio to the different internal fabrics formed during sample preparation (Wanatowski \& Chu, 2007; Lee et al., 2013). However, these relationships are hypothetical as the material fabric cannot be directly quantified in conventional laboratory tests. The DEM simulation data provide information on

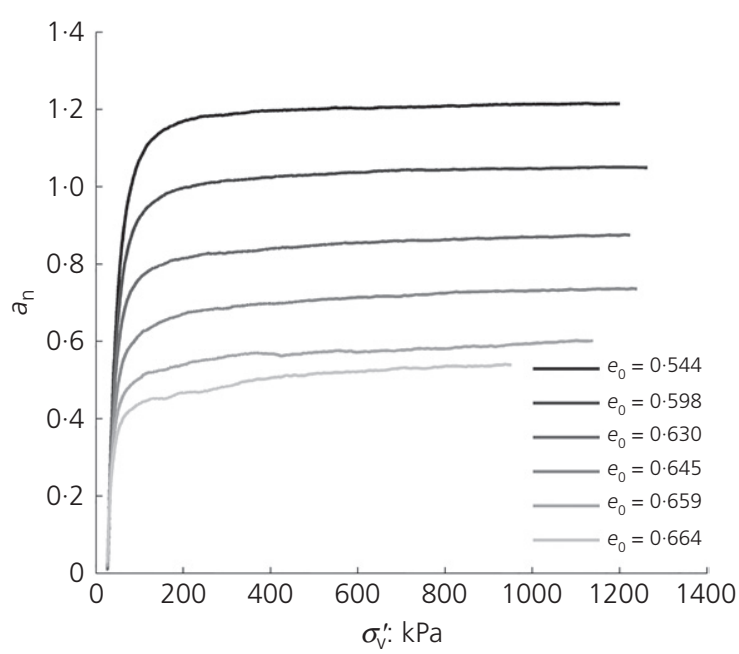

(a)

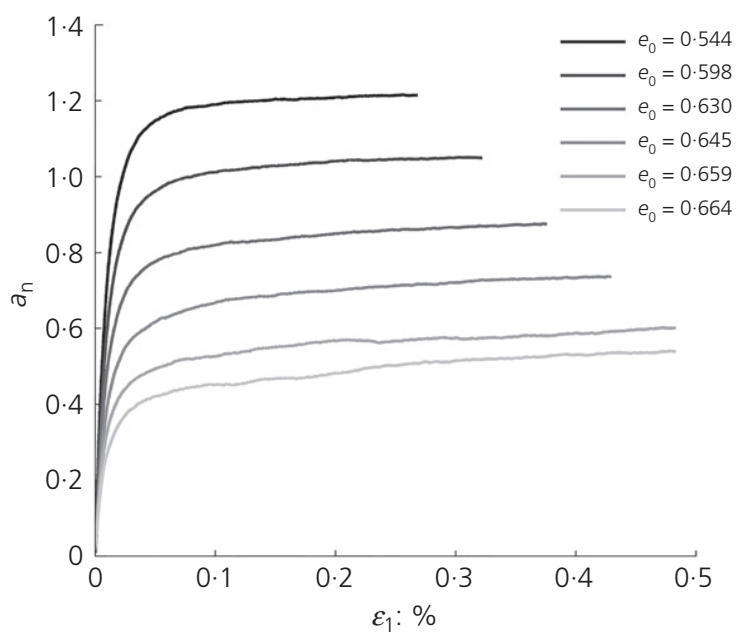

(b)

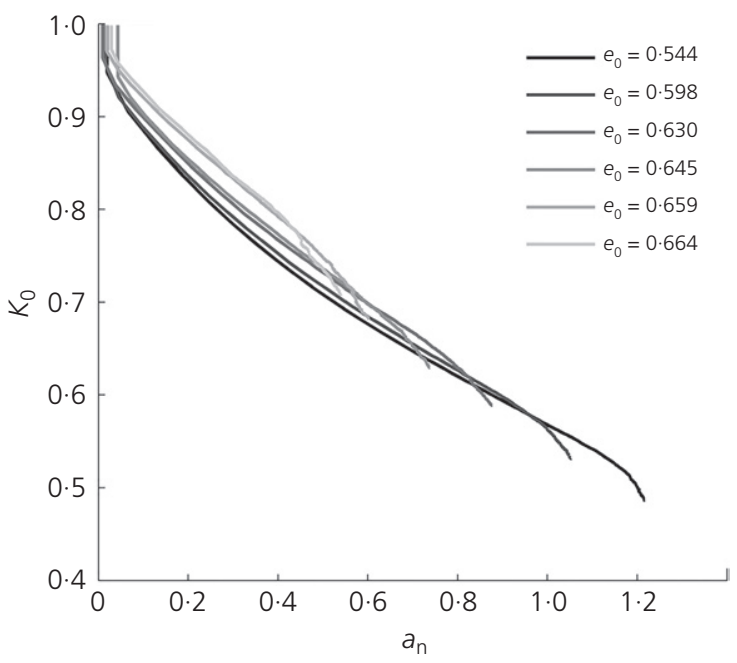

(c)

Fig. 7. Normal contact force anisotropy: (a) $a_{\mathrm{n}}$ versus $\sigma_{\mathrm{v}}^{\prime}$; (b) $a_{\mathrm{n}}$ versus $\varepsilon_{1}$; (c) $K_{0}$ versus $a_{\mathrm{n}}$

the direction of contacts. Satake (1982) proposed quantifying structural (fabric) anisotropy using the fabric tensor, which is defined as

$$
\vec{\Phi}_{i j}=\frac{1}{N_{\mathrm{c}}} \sum_{1}^{N_{\mathrm{c}}} n_{i} n_{j}
$$


where $N_{\mathrm{c}}$ is the total number of contacts and $n_{i}$ is the unit contact normal. The largest, intermediate and smallest eigenvalues of the fabric tensor are denoted as $\Phi_{1}, \Phi_{2}$ and $\Phi_{3}$, respectively. The ratio between $\Phi_{3}$ and $\Phi_{1}$ can be adopted to describe the degree of structural anisotropy, $F=\Phi_{3} / \Phi_{1}$, with the condition $\Phi_{3}=\Phi_{2}$ being closely satisfied. $F=0$ represents the highest degree of structural anisotropy while $F=1$ indicates an isotropic state. Figures 6(a) and 6(b) show the evolution of normalised $F\left(F / F_{0}\right)$ with $\sigma_{\mathrm{v}}^{\prime}$ and $\varepsilon_{1}$ respectively, $F_{0}$ being the degree of structural anisotropy after isotropic compression and is in the range 0.9904 to 0.9961. Figure 6(a) indicates that $F / F_{0}$ decreases as $\sigma_{\mathrm{v}}^{\prime}$ increases. Dense samples attained lower values of $F / F_{0}$ than looser samples and, as shown in Fig. 6(b), dense samples also showed a more rapid decrease in $F / F_{0}$ than looser samples during straining. Figure 6(c) plots $K_{0}$ against $F / F_{0}$ (up to $\varepsilon_{1}=0 \cdot 25 \%$ ), from which it is evident that $K_{0}$ values increase as $F / F_{0}$ values increase for all the packing densities considered. In general, while dense samples showed a higher degree of anisotropy, loose samples remained more isotropic. It is also noticeable that while $K_{0}$ decreases with $\sigma_{\mathrm{v}}^{\prime}$, the degree of structural anisotropy increases with $\sigma_{\mathrm{v}}^{\prime}$.

Rothenburg \& Bathurst (1989) analytically showed that the stress ratio is related to different sources of anisotropy, including geometrical anisotropy, normal contact force anisotropy and tangential contact force anisotropy, of which normal contact force anisotropy $\left(a_{\mathrm{n}}\right)$ dominates. It is worth exploring the $K_{0}-a_{\mathrm{n}}$ relationship for the DEM simulations. The definition of $a_{\mathrm{n}}$ follows Rothenburg \& Bathurst (1989) and Guo \& Zhao (2013), with the average normal contact force tensor expressed by equation (3) (where $\vec{\Phi}_{i j}{ }^{\prime}$ is the deviatoric part of $\vec{\Phi}_{i j}$ ) with its probability distribution given by equation (4) and $a_{i j}^{\mathrm{n}}=(15 / 2) \vec{F}_{i j}^{\prime \mathrm{n}} / \bar{f}^{0} \cdot \bar{f}^{0}=\vec{F}_{i i}^{\mathrm{n}}$ is the average normal contact force calculated considering the entire $\Omega$, different from the mean normal contact force averaged over all contacts. $a_{\mathrm{n}}$ is related to the second invariant of $a_{i j}{ }^{\mathrm{n}}$ as $a_{\mathrm{n}}=\left[(3 / 2) a_{i j}{ }^{\mathrm{n}} a_{i j}{ }^{\mathrm{n}}\right]^{1 / 2}$.

$$
\begin{aligned}
& \vec{F}_{i j}^{\mathrm{n}}=\frac{1}{4 \pi} \int_{\Omega} \bar{f}_{\mathrm{n}}(\Omega) n_{i} n_{j} \mathrm{~d} \Omega \\
& =\frac{1}{N_{\mathrm{c}}} \sum_{1}^{N_{\mathrm{c}}} \frac{f_{\mathrm{n}} n_{i} n_{j}}{1+(15 / 2) \bar{\Phi}_{i j}{ }^{\prime} n_{k} n_{l}} \\
& \bar{f}_{\mathrm{n}}(\Omega)=\bar{f}^{0}\left[1+a_{i j}^{\mathrm{n}}\right]
\end{aligned}
$$

Figures 7(a) and 7(b) indicate the evolution of $a_{\mathrm{n}}$ with $\sigma_{\mathrm{v}}^{\prime}$ and $\varepsilon_{1}$, respectively. There is a clear influence of the initial void ratio, with denser samples attaining higher values of $a_{\mathrm{n}}$

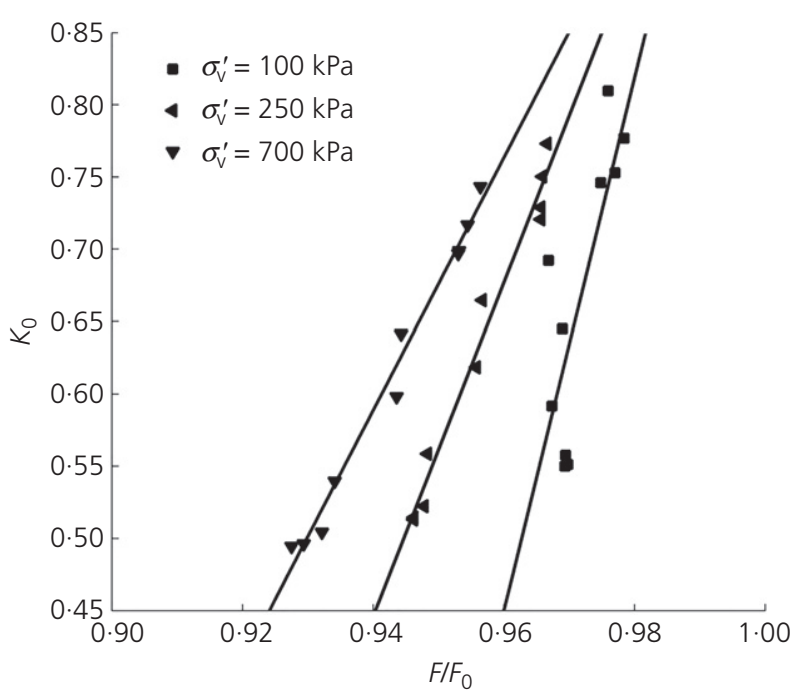

(a)

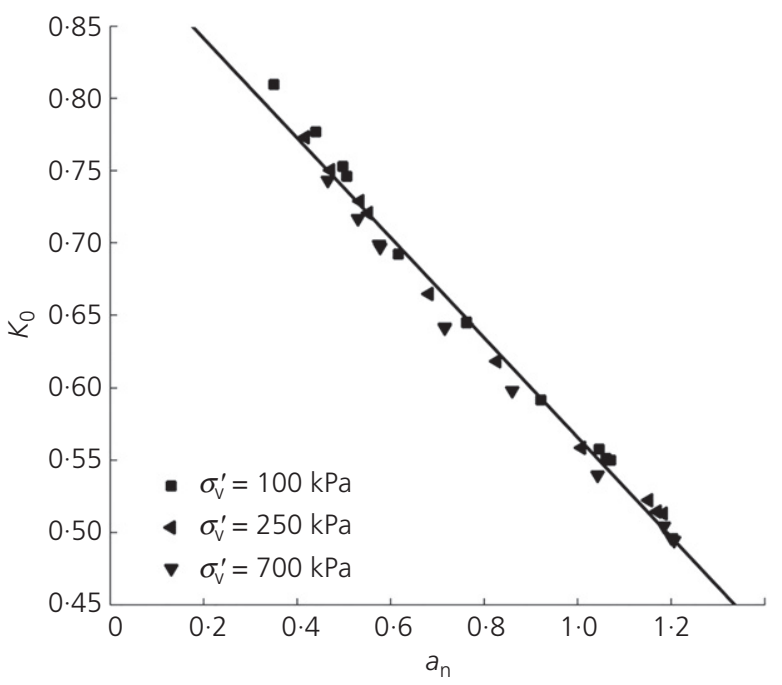

(c)

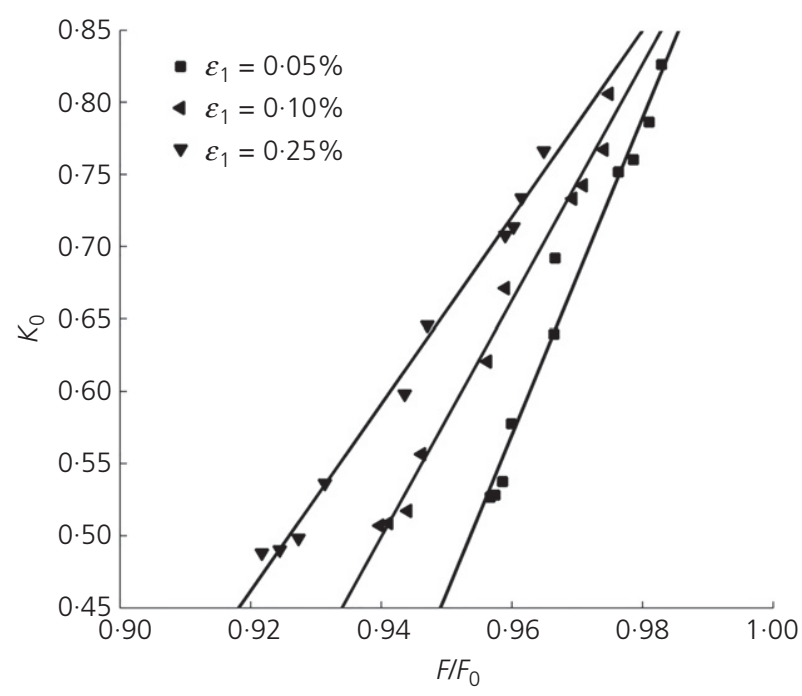

(b)

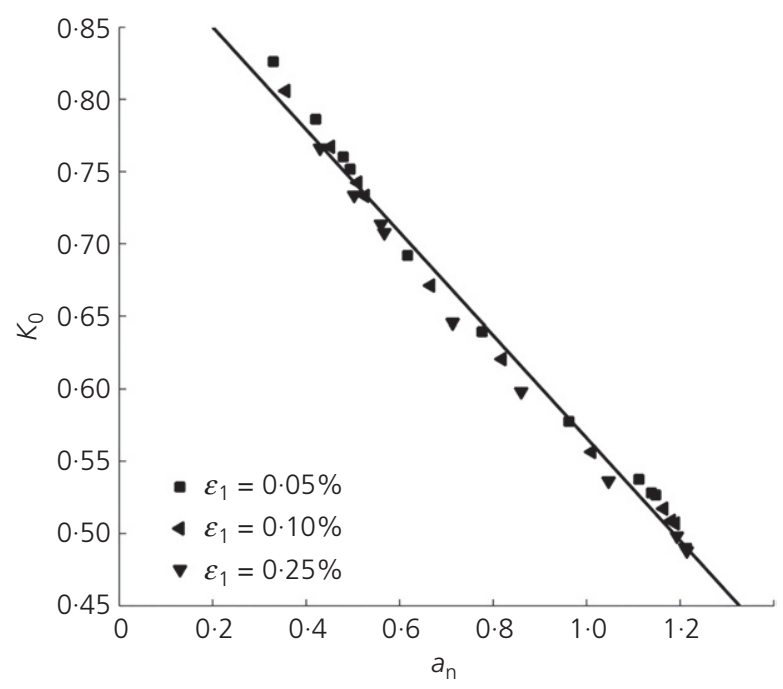

(d)

Fig. 8. $K_{0}$ versus $F / F_{0}$ at different $\sigma^{\prime}{ }_{v}(a)$ and different stages of $\varepsilon_{1}$ (b). $K_{0}$ against $a_{n}$ at different $\sigma^{\prime}{ }_{v}(\mathrm{c})$ and different stages of $\varepsilon_{1}$ (d) 
than looser ones. Figure 7(b) shows that all samples attained an almost constant value of $a_{\mathrm{n}}$ after $0.05 \%$ of $\varepsilon_{1}$. Figure 7(c) plots $K_{0}$ against $a_{\mathrm{n}}$, where a similar path is noticed for all the samples.

The relationships between $K_{0}$ and $F / F_{0}$ at different values of $\sigma_{\mathrm{v}}^{\prime}$ and $\varepsilon_{1}$ are presented in Figs 8(a) and 8(b), respectively. In both cases, and for all stages, a linear relationship can be found between $K_{0}$ and $F / F_{0}$ in which higher values of $K_{0}$ are always related to higher $F / F_{0}$. The relationships between $K_{0}$ and $a_{\mathrm{n}}$ at different values of $\sigma_{\mathrm{v}}^{\prime}$ and $\varepsilon_{1}$ are presented in Figs 8(c) and 8(d), respectively. Regardless of stress or strain levels, the relationship between $K_{0}$ and $a_{\mathrm{n}}$ can be represented by a single line that shows lower values of $K_{0}$ at higher $a_{\mathrm{n}}$.

For a clearer illustration of the influence of structural anisotropy and normal contact force anisotropy, Figs 9(a) and 9(b) present contact rose diagrams for a dense (test K0-1) sample and a loose (test K0-9) sample at the same level of $\sigma_{\mathrm{v}}^{\prime}$ considering the projections onto the $x-z$ vertical plane using an angular increment of $10^{\circ}$. The radial length of each bin indicates the number of contacts oriented within the angle defining the bin. The colour of each bin is proportional to the sum of the normal contact forces that are present in that bin. For the dense sample, the stronger contacts that carry higher forces are preferentially aligned in the loading (i.e. vertical) direction, while the weaker contacts (transmitting lower force) tend to be oriented orthogonal to the loading direction. A larger number of contacts are present in the vertical direction than in the horizontal direction, leading to lower values of $F$. More stress is transmitted in the vertical direction than in the horizontal direction, resulting in a larger value of $\sigma_{\mathrm{v}}^{\prime}$ and a smaller value of $\sigma_{\mathrm{h}}^{\prime}$. The loose sample presents a more isotropic distribution of both contact direction and force magnitude, yielding higher values of $F$. Moreover, contact forces transmitted in the horizontal direction are closer in magnitude to those transmitted in the vertical direction,

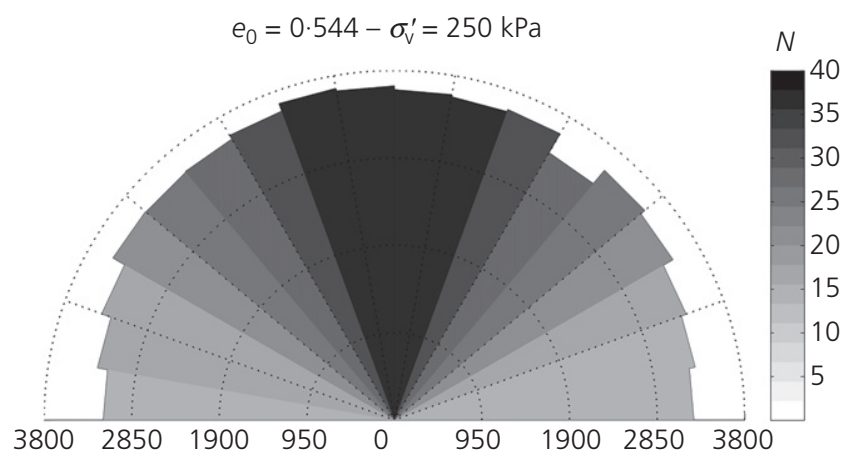

(a)

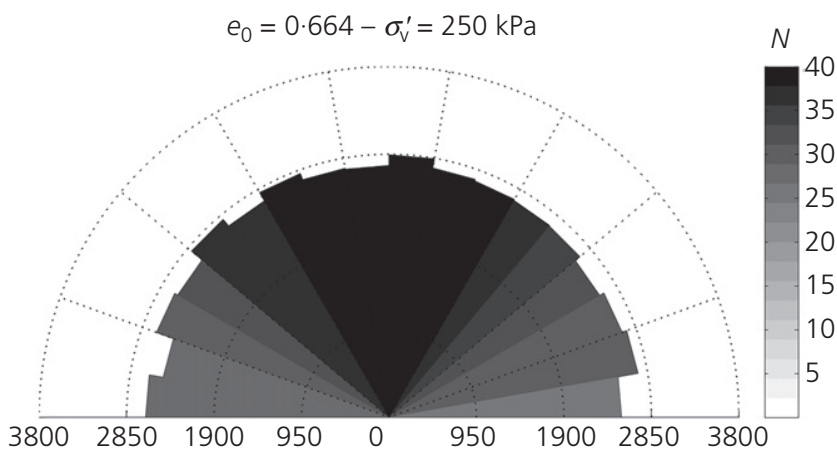

(b)

Fig. 9. Comparison of contact rose diagrams at the same value of $\sigma^{\prime}{ }_{v}$ for a dense sample (a) and a loose sample (b) making the values of $\sigma_{\mathrm{v}}^{\prime}$ and $\sigma_{\mathrm{h}}^{\prime}$ more alike. This explains why $K_{0}$ values decrease with increasing packing density.

\section{CONCLUSIONS}

One-dimensional tests on initially isotropic samples with a range of void ratios were simulated using the discrete element method. The resulting dependency of $K_{0}$ on void ratio qualitatively agrees with previously published laboratory tests (i.e. $K_{0}$ increases as void ratio increases). A power-law relationship between $K_{0}$ and $e_{0}$ was observed and this relationship depends on the stress level and vertical strain. Three definitions of $\phi^{\prime}$ were considered when applying Jaky's expression $\left(\phi_{\text {mob }}^{\prime}, \phi_{\mathrm{p}}^{\prime}\right.$ and $\left.\phi_{\mathrm{cv}}^{\prime}\right)$ and compared to the measured $K_{0}$. While the use of $\phi_{\mathrm{p}}^{\prime}$ gave the best match at lower void ratios and $\phi_{\mathrm{cv}}^{\prime}$ reported fair predictions for looser samples, none of these expressions gave a good match with the measured $K_{0}$ values for the entire range of void ratio and stress levels considered. Micro-scale analysis revealed that the variation of $K_{0}$ with void ratio is related to the degree of both structural anisotropy and normal contact force anisotropy. $K_{0}$ decreases linearly with increasing structural anisotropy, quantified using the ratio of major and minor principal values of the fabric tensor $F$. The $K_{0}-F$ relationship was seen to depend on stress and strain level while a unique relationship, independent of stress or strain level, was found between $K_{0}$ and $a_{\mathrm{n}}$. Dense samples had higher degrees of structural and normal contact force anisotropy at all test stages while loose samples remained more isotropic with lower normal contact force anisotropy. Loose samples were found to transmit similar stresses in all directions while, for dense samples, stress transmission coincided preferentially with the vertical loading direction. Therefore, $K_{0}$ values for dense samples are smaller than those of loose samples. The results of this study support the hypothesis of Lee et al. (2013) and Wanatowski \& Chu (2007) that $K_{0}$ values are related to the internal structure.

\section{ACKNOWLEDGEMENTS}

This research was supported and financed by The University of Hong Kong Seed Funding Programme for Basic Research. Mr Lopera Perez would like to thank the IT Department at The University of Hong Kong for providing access to the high-performance computer HPCPOWER2 in order to conduct the simulations presented in this work.

\section{REFERENCES}

Bagi, K. (1996). Stress and strain in granular assemblies. Mech. Mater. 22, No. 3, 165-177.

Been, K. \& Jefferies, M. G. (1985). A state parameter for sands. Géotechnique 35, No. 2, 99-112.

Chu, J. \& Gan, C. L. (2004). Effect of void ratio on $K_{0}$ of loose sand. Géotechnique 54, No. 4, 285-288.

da Cruz, F., Emam, S., Prochnow, M., Roux, J. N. \& Chevoir, F. (2005). Rheophysics of dense granular materials: discrete simulation of plane shear flows. Phys. Rev. E 72, No. 2, 021309.

Guo, N. \& Zhao, J. (2013). The signature of shear-induced anisotropy in granular media. Comput. Geotech. 47, 1-15.

Guo, P. J. \& Stolle, D. F. E. (2006). Fabric and particle shape influence on $K_{0}$ of granular materials. Soils and Found. 46, No. 5, $639-652$.

Hendron, A. J. (1963). The behaviour of sand in one-dimensional compression. $\mathrm{PhD}$ thesis, University of Illinois at Urbana Champaign, Urbana, IL, USA.

Huang, X., Hanley, K. J., O’Sullivan, C. \& Kwok, C. Y. (2014a). Effect of sample size on the response of DEM samples with a realistic grading. Particuology 15, 107-115.

Huang, X., Hanley, K. J., O’Sullivan, C. \& Kwok, C. Y. (2014b). Exploring the influence of interparticle friction on critical state 
behaviour using DEM. Int. J. Numer. Anal. Methods 38, No. 12, 1276-1297.

Jaky, J. (1944). A nyugalmi nyomas tenyezoje (The coefficient of earth pressure at rest). J. Soc. Hung. Eng. Arch. 78, No. 22, 355-358 (in Hungarian).

Ladd, C. C., Foott, R., Ishihara, K., Schlosser, F. \& Poulus, H. G. (1977). Stress-deformation and strength characteristics. Proc. 9th Int. Conf. on Soil Mechanics and Foundation Engineering, Tokyo. Tokyo: Japanese Society of Soil Mechanics and Foundation Engineering, vol. 2, pp. 421-494.

Lee, J., Yun, T. S., Lee, D. \& Lee, J. (2013). Assessment of $K_{0}$ correlation to strength for granular materials. Soils and Found. 53, No. 4, 584-595.

Mesri, G. \& Hayat, T. M. (1993). The coefficient of earth pressure at rest. Can. Geotech. J. 30, No. 4, 647-666.

Mesri, G. \& Vardhanabhuti, B. (2007). Coefficient of earth pressure at rest for sands subjected to vibration. Can. Geotech. J. 44, No. $10,1242-1263$.

GDR MiDi (Groupement de Recherche Milieux Divisés) (2004). On dense granular flows. Eur. Phys. J E 14, No. 4, 341-365.

Northcutt, S. \& Wijewickreme, D. (2013). Effect of particle fabric on the coefficient of lateral earth pressure observed during one-dimensional compression of sand. Can. Geotech. J. 50, No. 5, 457-466.

Okochi, Y. \& Tatsuoka, F. (1984). Some factors affecting $K_{0}$-values of sand measured in triaxial cell. Soils and Found. 24, No. 3, 52-68.
Plimpton, S. (1995). Fast parallel algorithms for short-range molecular dynamics. J. Comput. Phys. 117, No. 1, 1-19.

Potyondy, D. O. \& Cundall, P. A. (2004). A bonded-particle model for rock. Int. J. Rock. Mech. Mining Sci. 41, No. 8, 1329-1364.

Rothenburg, L. \& Bathurst, R. J. (1989). Analytical study of induced anisotropy in idealized granular materials. Géotechnique 39, No. 4, 601-614.

Satake, M. (1982). Fabric tensor in granular materials. In Deformation and failure of granular materials (P. A. Vermeer \& H. J. Luger (eds)). Rotterdam: Balkema, pp. 63-68.

Talesnick, M. L. (2012). A different approach and result to the measurement of $K_{0}$ of granular materials. Géotechnique 62, No. 11, 1041-1045.

Thornton, C. (2000). Numerical simulations of deviatoric shear deformation of granular media. Géotechnique 50, No. 1, 43-53.

Wanatowski, D. \& Chu, J. (2006). Stress-strain behaviour of a granular fill measured by a new plane-strain apparatus. Geotech. Test J. 29, No. 2, 149-157.

Wanatowski, D. \& Chu, J. (2007). $K_{0}$ of sand measured by a plane-strain apparatus. Can. Geotech. J. 44, No. 8, 1006-1012.

Wood, D. M. (1990). Soil behaviour and critical state soil mechanics. Cambridge: Cambridge University Press.

Wroth, C. P. (1972). General theories of earth pressure and deformation. Proc. 5th Euro. Conf. on Soil Mechanics and Foundation Engineering, Madrid. Madrid: Sociedad Española de Mecanica del Suelo y Cimentaciones, vol. 2, pp. 33-52. 